\title{
The Effects of Low Altitude Training on Erythropoietin Response and Hematological Variables in Elite Female Fencers
}

\author{
Veli Volkan Gürses*, Mustafa Şakir Akgül \\ School of Physical Education and Sports, Kastamonu University, Turkey
}

Copyright(C2018 by authors, all rights reserved. Authors agree that this article remains permanently open access under the terms of the Creative Commons Attribution License 4.0 International License

\begin{abstract}
The Live High-Train High (LHTH) model altitude training is required to sojourn over $2000 \mathrm{~m}$ more than 3 weeks. In such altitudes response that may cause decreased living, sleeping and training quality. In these cases coaches may approach with suspicion to LHTH can be harmful for their training intensity edgewise training quality. The aim of this study was to investigate the effect of 12 days $1850 \mathrm{~m}$ training on some hematological parameters in the world-class woman fencers. Ten female fencers (age $21.50 \pm 3.69$, height $167.16 \pm 3.88 \mathrm{~cm}$, weight $59.11 \pm 3.437 \mathrm{~kg}$ ) voluntarily participated in this study. The athletes were investigated low altitude training camp at $1850 \mathrm{~m}$. The blood samples were taken before and after the moderate altitude training for analyzing erythropoietin (EPO), red blood cell (RBC), hemoglobin (HB) and hematocrit (HCT) concentration levels. The paired sample $\mathrm{t}$-test was used for determine the differences pre and posttests results, significance levels $\mathrm{p}<0.05$ Results shows that concentrations of EPO increased significantly after twelve days low altitude training. However RBC, HB, HCT concentrations were unaffected by the hypoxic stimulus. The results of this study have suggested that the 12 days LHTH training at $1850 \mathrm{~m}$ can be stimulated EPO. This means $1850 \mathrm{~m}$ altitude possibly induces hypoxic effect. Nevertheless, 12 days altitude training is not enough to enhance performance related blood markers.
\end{abstract}

Keywords Live High, Train High, Erythropoietin, Red Blood Cell, Hemoglobin, Hematocrit

\section{Introduction}

Competitive athletes and coaches from wide range of sports frequently use altitude training methods to improve sea level endurance performance [1]. It is well known that resting arterial oxygen saturation $\left(\mathrm{SaO}_{2}\right)$ is well maintained at low altitudes between sea level and 1500m. The $\mathrm{SaO}_{2}$ starts to progressively decline at higher altitudes as a result of partial oxygen pressure drop. Although $\mathrm{SaO}_{2}$ can reach lower than $80 \%$ depending on altitude level, the fractional concentration of oxygen remains the same [2]. Therefore, inspired oxygen pressure decreased, which results in hypoxia that disturbs balance of homeostasis. Several physiological and metabolic regulations are adjusted to maintain the tissue oxygenation in unbalanced homeostasis conditions. The regulations are generally attributed to hematological, cardiovascular and ventilator mechanisms [3]. However, training at altitude leads to enhanced total hemoglobin mass, erythropoietin volume, red cell volume, muscle buffering capacity, capillary density, maximal aerobic capacity, exercise capacity and exercise economy. Sports performance is dependent on many parameters: physical, motric, biochemical, physiological, psychological, training, rehabilitation, environment etc. [4-5]. Various types of altitude training have been suggested in literature [6,7]. The most remarkable method is classical model which commonly used by sport specialists. The classic model involves travelling to moderate altitude 2000-3000m [1] and exposure to high altitude for 3-4 weeks $[2,3,8]$. One physiological rationale is to sojourn these ambient increase endogenous erythropoietin levels in natural altitudes [9]. Athletes train, live and spend all their times to stimulate their bodies to increase erythropoietin production. The classical model called "Live High - Train High" (LHTH) model. It is well known that long-term acclimatization to LHTH induces polycythemia with increase in red blood cell (RBC) count and hemoglobin concentration (HB). Studies showed that the oxygen-carrying capacity of the blood and work capacity increase with LHTH [10-13]. However, in some obligatory cases like necessity of acclimatization to competitions low or moderate altitude ambient or although rare to move away from hot climate conditions, as short term (less than 3 weeks) low or moderate altitude camps 
are commonly selected for using altitude effect to lead to performance gain by sports specialist [14]. Recent studies revealed that erythropoietin (EPO) adaptation induce hemoglobin-mass (Hbmass) by raising 300 hours (approximately 12-13 day) of exposure natural moderate altitude of exposure (increasing $1 \%$ per 100 hours observed) [15]. These camps are allowed for approximately two weeks which can be accepted lower bound of altitude training by Garvican et al [15], under 2000m altitude. On the other hand, achieving over $2000 \mathrm{~m}$ (especially close to $3000 \mathrm{~m}$ ) and sojourning at these altitudes more than 2 weeks may cause decreased living, sleeping and training quality [16]. Studies show that the influence of low altitudes $(<2000 \mathrm{~m})$ on oxygen related blood unit adaptation is unclear and such short moderate altitudes camps may be insufficient to stimulate significant increases in hemoglobin mass and other oxygen markers [17]. However, a few reports mentioned positive effects of LHTH model with low altitude on erythropoietin level, HB-mass, HCT [18-20]. Therefore, it is necessary to understand the physiological effects of low altitude upon lowlanders arriving at altitude and the impact of these effects on sporting performance. To date, data related to sex-specific $\mathrm{Hb}$-mass responses to altitude training have not been available. Theoretically, one might expect lower $\mathrm{Hb}$-mass increases in female than in male athletes due to sex-specific respiratory reactions at altitude. The female hormones estrogen and progesterone augment the hypoxic ventilatory response and prevent pronounced decreases in arterial $\mathrm{pO} 2$ and $\mathrm{O} 2$ saturation that occurs in men. As a result, higher $\mathrm{sO} 2$ and lower HB-mass are observed in untrained premenopausal women compared to postmenopausal women living permanently at $2,600 \mathrm{~m}$ [21]. The aim of this study was to investigate the effect of short term (which can assumed lower bound; 12 days) low altitude training on some hematological parameters in the world-class woman fencers.

\section{Materials and Methods}

\subsection{Subjects}

Fourteen females from a world class women fencing team voluntarily participated in this study. The athletes were investigated during short term (12 days) low altitude training camp at $1850 \mathrm{~m}$. All participants residence under $1000 \mathrm{~m}$ altitude and did not locate moderate or high altitude during last 30 days. Four athletes who were in the period of menstruation were not included in posttest. Ten athletes (age $21.50 \pm 3.69 \mathrm{y}$, height $167.16 \pm 3.88 \mathrm{~cm}$, weight 59.11 $\pm 3.437 \mathrm{~kg}$ ) were able to complete pre and posttests. All athletes signed a written and informed consent before all testing and all test procedures were approved by Karabük University ethics committee for clinical research with the protocol number of $1 / 22$.

\subsection{Experimental Protocol}

The research's special aim was to evaluate the effect of 12 days LHTH training at $1850 \mathrm{~m}$ on erythropoietin, red blood cell ( $\mathrm{Rbc}$ ) count and hemoglobin concentration $(\mathrm{Hb})$ and HCT in word class female fencers. The research experiment was descriptive in nature and followed by a repeated - measurement design in which each participants served as her own control. Fencers followed their own training program which was 12 aerobic based conditioning training and 8 aerobic based technical trainings interspersed by three rests. The training program design was based on increased loading principles. Researchers did not interfere camp training program. The daily training time was 3-5 hours. The measurements were made during the preparation period of fencers' annual training program. Low altitude (Ilgaz Mountain National Park, 1850m) was used as the camp location. The camp lasted 12 days. Athletes stayed in Kastamonu (774m) where pre-test blood samples were taken approximately 24 hours before arriving at the camp location. After taking the blood samples, the athletes moved to the training camp location. Post-test blood samples were taken after 14-16 hours following the last workout. Moreover, athletes were requested to inform researchers about their menstrual periods.

\subsection{Hematological measures}

Blood samples were taken from the participants at the beginning and end of the camp. Blood samples $(8 \mathrm{ml})$ were taken from antecubital vein in the sitting position. Blood samples were taken with blood sample tubes (BD Vacutainer $\left.{ }^{\circledR}\right)$. Blood samples were centrifuged at 3000 rpm to separate plasma. Samples were sent to be investigated for such blood variables as red blood cell (Rbc), hemoglobin ( $\mathrm{Hb})$ and hematocrit (Hct) concentrations. Samples were studied with Siemens ADVIA 2120i equipment on the same day. Blood samples were stored at a $-85^{\circ} \mathrm{C}$ until they were analysed for Erythropoietin (EPO) concentration. EPO concentrations were measured in plasma.

\subsection{Statistical Analysis}

SPSS 22 software program was used for statistical evaluation. Descriptive statistics were given in the form of mean and standard deviation. The Shapiro Wilk Test of normality was used to determine if the data's were normally distributed. Mean scores of dependent variables (blood cell (Rbc), hemoglobin $(\mathrm{Hb})$ and hematocrit (Hct) and erythropoietin (Epo)) were compared before and after altitude training. The paired sample T-test was used to compare pre and posttests values of dependent variables at a significance levels of $p<0.05$. 


\section{Results}

The anthropometric parameters are in in the normal limits according with the age and sport practiced (Table 1.)

Table 1. Descriptive statistics of anthropometric parameters of the subjects

\begin{tabular}{cccc}
\hline Parameters & $\mathrm{n}$ & Mean & $\mathrm{SD}$ \\
\hline Age (year) & 10 & 21.50 & 3.69 \\
Height $(\mathrm{cm})$ & 10 & 167.16 & 3.88 \\
Body Weight $(\mathrm{kg})$ & 10 & 59.11 & 3.44 \\
\hline
\end{tabular}

n- Number, SD - standard deviation

$\mathbf{A}$

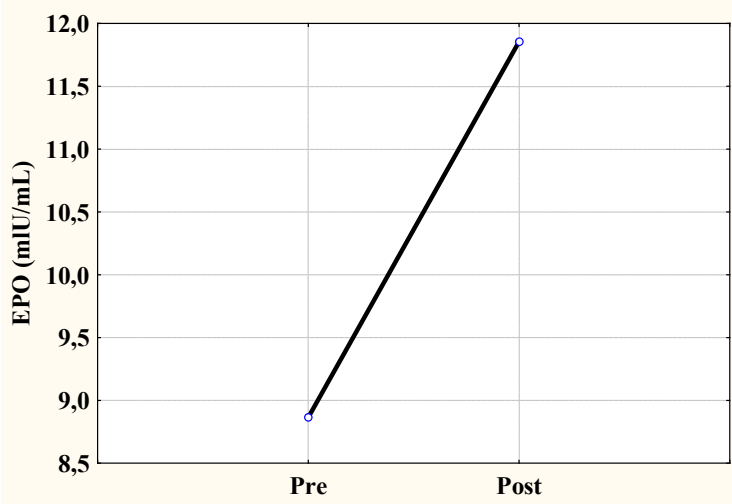

B

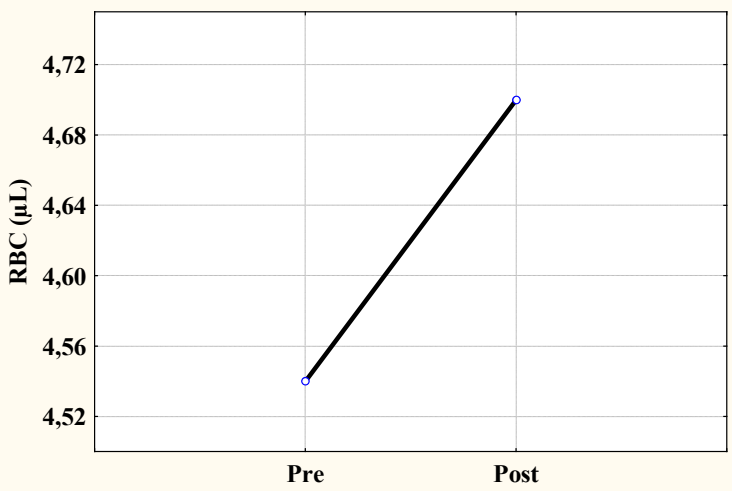

Figure 1. Significant change in EPO $(\mathrm{p}<0.05)$ and nonsignificant change in $\mathrm{RBC}(\mathrm{p}>0.05)$ pre and posttest

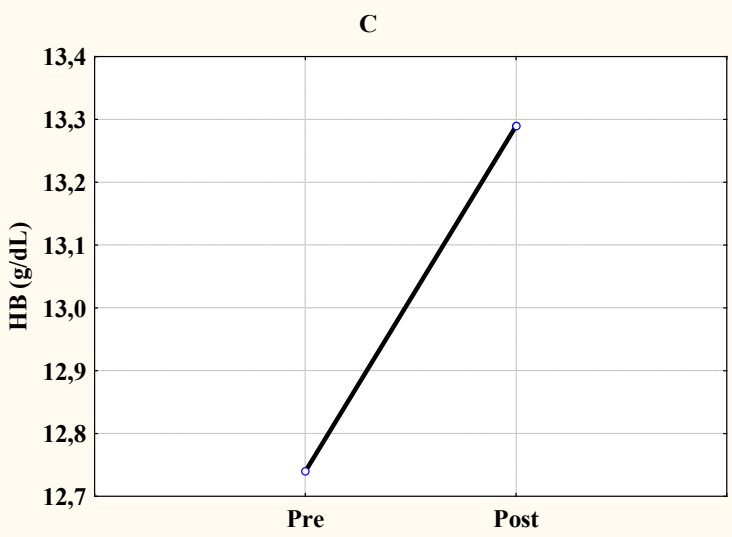

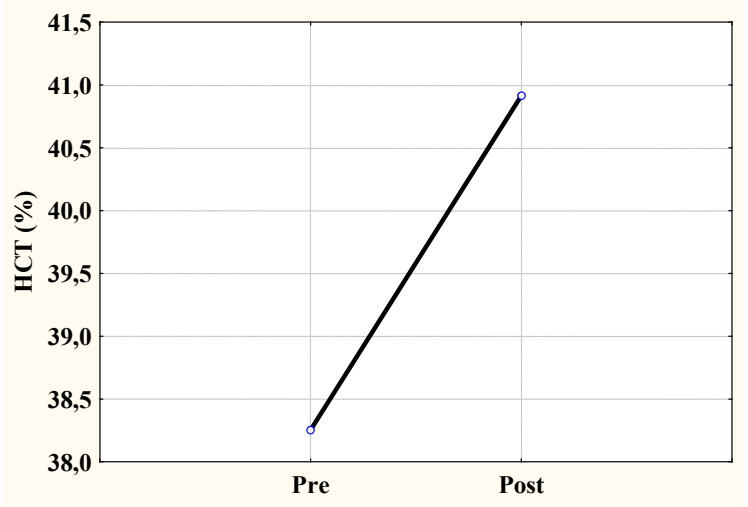

Figure 2. Changes in $\mathrm{HB}$ and HCT pre and posttest $(\mathrm{p}>0.05)$

In female fencers (Table 2.), EPO $(8.87 \pm 4.15$ to $11.86 \pm$ $4.60 \mathrm{mlU} / \mathrm{mL}, \mathrm{p}<0.05)$ significantly increased at the end of LHTH training period (12 days sojourn) compared to sea level values. 12 days altitude exposure and trainings affected athletes EPO levels which increased approximately $33.71 \%$. The performance related hematological values RBC, HB and HCT little increased; $3.5 \%, 4.3 \%$ and $6.9 \%$, respectively. The results represented no significant changes $(\mathrm{p}>0.05)$.

Table 2. Comparison of Pre-Post Blood Parameters Values

\begin{tabular}{ccccccc}
\hline & Tests & $\mathrm{n}$ & Mean & $\mathrm{SD}$ & $\mathrm{t}$ & $\mathrm{p}$ \\
\hline $\begin{array}{c}\mathrm{EPO} \\
(\mathrm{mlU} / \mathrm{mL})\end{array}$ & pre & 10 & 8.87 & 4.15 & & \\
\hline \multirow{2}{*}{$\mathrm{RBC}(\mu \mathrm{L})$} & pre & 10 & 11.86 & 4.60 & -3.84 & 0.004 \\
& post & 10 & 4.70 & 0.35 & -1.63 & 0.138 \\
\hline \multirow{2}{*}{$\mathrm{HB}(\mathrm{g} / \mathrm{dL})$} & pre & 10 & 12.74 & 0.67 & -2.038 & 0.072 \\
& post & 10 & 13.29 & 0.74 & & \\
\hline \multirow{2}{*}{$\mathrm{HCT}(\%)$} & pre & 10 & 38.26 & 2.72 & -2.21 & 0.054 \\
& post & 10 & 40.92 & 2.25 & & \\
\hline
\end{tabular}

$\mathrm{n}$ - Number, SD-standard deviation, t-Paired sample $\mathrm{t}$ test value, $\mathrm{p}$ probability level

\section{Discussion}

Major finding of the present study was that 12 days short period LHTH training camp at low altitude $(1850 \mathrm{~m})$ resulted in increased erythropoietin activity. The changes corresponded to $33.71 \%$. However, this change was not sufficient to induce a significant increase on blood oxygen carrying capacity in female fencers. A key factor for acclimatization to altitude is increase in EPO production [3]. The decrease in arterial oxygen pressure $\left(\mathrm{P}_{\mathrm{a}} \mathrm{O}_{2}\right)$ stimulates EPO production in hypoxic ambit. The threshold of $\mathrm{P}_{\mathrm{a}} \mathrm{O}_{2}$ levels are accepted approximately $70 \mathrm{mmHg}$ which corresponds to an altitude over $1600 \mathrm{~m}$ [22]. Frese \& Friedmann-Bette [23], supports this idea by revealing that exposure of altitude at $1300 \mathrm{~m}-1650 \mathrm{~m}$ with LHTH training for three weeks induced increment EPO level and Hbmass. 
Generally low natural altitudes $(<2000 \mathrm{~m})$ are assumed not to be sufficient to induce EPO production levels [26]. Literature findings have suggested that LHTH model should be involved in an exposure of over $2000 \mathrm{~m}$ altitude at least for three weeks to induce altitude hypoxic effect $[1,3,25]$. Gore et al. [26], have showed the median altitude was $2320 \mathrm{~m}$ for LHTH models training in their meta-analysis study. However, Garvican-Lewis et al [8], recently reported that $1850 \mathrm{~m}$ altitude significantly increases EPO level and Hbmass in contrast to previous assumption. This finding is similar with our results when the nonsignificant $\mathrm{Hb}$ change $(4.3 \%)$ is taken into consideration in this regard. Earlier limited number of study question that low altitudes (1500-2000m) affect hematological parameters [23,27-29]. Friedmann et al [19], observed that boxers' Epo level change after LHTH training with an altitude of $1800 \mathrm{~m}$ for 18 days. Asano et al [18], reported increased EPO levels in swimmers LHTH at $1886 \mathrm{~m}$ for 21 days on the 1 st and 12th days. Heinicke et al. [30], have revealed that EPO level remained elevated in altitude. The results of study are in agreement with these investigations of low altitude on EPO. The improvement in EPO level induced by LHTH plays an important role in changes of $\mathrm{RBC}$ volume and $\mathrm{Hb}$ mass. The common finding upon exposure to hypoxia is a transient increase in hemoglobin concentration and hematocrit because of a rapid decrease in plasma volume followed by an increase in erythropoiesis per se. The most important adaptation related to sport performance especially aerobic power is increasing blood oxygen-carrying capacity. These changes only appeared in case of increasing RBC. It is well known that the availability of oxygen in the kidneys and liver is the main regulator of the production of EPO. Lack of oxygen stimulates low plasma oxygen tension increasing EPO production. The activation of EPO receptors in the bone marrow enhances the mitosis and differentiation of specific erythroid progenitor cells, resulting in the production of new RBC in case of existing sufficient $\mathrm{Hb}$. Twenty one day exposure to altitude is required for production of new cells released to the bloodstream [10]. The changes in RBC volume and $\mathrm{Hb}$ mass are induced by exposure hours in sufficient hypoxia corresponding to at least $12 / \mathrm{h}$ per day [25]. To maintain the physiological effect of altitude, it is necessary to spend time at the altitude depending on the acclimatization periods. In this study the LHTH model was slightly shorter than these suggestions. However, recently Gore et al [12], have revealed two weeks (corresponding to 336 h) stay at altitude may be sufficient to increase HB approximately $4 \%$ in their meta-analysis investigation. In our study, the time spent at altitude was 12 days (corresponding to $288 \mathrm{~h}$ ) shorter than Gore's recommendation. In this case, some investigations have demonstrated that 100 hours at altitude is needed for an increase of $\mathrm{Hb}$ mass approximately $1 \%[15,31]$. We calculated the change in $\mathrm{Hb}$ as $4.3 \%$ which is similar to the above-mentioned result. In the light of information provided by earlier studies, for example, Gore et. al., [26], investigated effect of LHTH model for 4 weeks exposure at $1740 \mathrm{~m}$ altitude. Their findings have showed no any significant change in $\mathrm{Hb}$ and $\mathrm{RBC}$. In addition, other two articles did not report any positive changes on $\mathrm{Hb}$ at altitude between $1500-2000 \mathrm{~m}$ for 20 days exposure [17, 19]. Asano et al. [18], carried out their investigation at $1,886 \mathrm{~m}$ for 21 days and their results have showed no any significant change in $\mathrm{Hb}, \mathrm{RBC}$ and Hct on the 3th, 16th, 30st days. Garvican-Lewis et al [8], results may support this finding in view of the fact that they found 3\% increase in $\mathrm{Hb}$ and significant increase in $\mathrm{RBC}$ after 3 weeks of LHTH exposure at $1800 \mathrm{~m}$. All these results assumed support our results. Nadarajan et al [20], did not observe any change in HCT and $\mathrm{Hb}$ on the $9^{\text {th }}$ and $16^{\text {th }}$ days of investigation during 21 days training at an altitude of $1905 \mathrm{~m}$. Similiarly, Heinicke et al [30]. Have not encountered any significant change in RBC, HB and HCT on the $16^{\text {th }}$ day of experiment. It seems that 12 days LHTH training at low altitude is not sufficient to enhance blood oxygen-carrying capacity. It are in agreement with previous investigations of low altitude. Only one report we found which is not similar with our results. Badau et.al [27], founding's revealed that a significant changes on $\mathrm{RBC}, \mathrm{Hb}$ at $1805 \mathrm{~m}$ however athletes have been exposed this altitude for 28 days. It means that to exposure $1850 \mathrm{~m}$ altitude enhance EPO even short times in low altitude however, this enhancement not sufficient to induce blood oxygen-carrying capacity related $\mathrm{RBC}, \mathrm{HCT}$ and $\mathrm{Hb}$. As for limitations of the study, although twenty volunteers were foreseen to participate in the study, only ten volunteers accepted to be a part of this study. Coaches did not let us interfere training plan so aerobic capacity and endurance performance tests could not be conducted. Therefore, we did not receive trainings contents during the altitude camp. Thus, the present research was descriptive nature. Moreover, iron may play an important role for altitude adaptations. The iron level should be controlled before sojourn altitude. A questionnaire may be used for acute mountain sickness.

\section{Conclusions}

The results of this study have suggested that the 12 days LHTH training at $1850 \mathrm{~m}$ can be stimulated EPO. This means $1850 \mathrm{~m}$ altitude possibly induces hypoxic effect. Nevertheless, 12 days altitude training is not enough to enhance performance related blood markers. The LHTH model require to train at over $2000 \mathrm{~m}$ more than 2 weeks. In such altitudes may cause decreased living, sleeping and training quality [16]. In these case coaches assumed that altitude can be harmful for their training intensity edgewise training quality especially in nonaerobic endurance sports. In addition coaches selected altitude camps in some obligatory cases like to move away from hot climate 
conditions as short term (less than 3 weeks). The knowledge of low altitude training is limited as mentioned.

\section{Acknowledgements}

Authors declare no conflict of interest.

\section{REFERENCES}

[1] Bartsch, P.; Saltin, B.; Dvorak, J.; Federation Internationale de Football, Association (2008) Consensus statement on playing football at different altitude. Scand J Med Sci Sports, 18, 96-99, 2008

[2] Mazzeo, R.S. Physiological responses to exercise at altitude. Sports Medicine, 38(1), 1-8, 2008

[3] Płoszczyca, K.; Langfort, J.; Czuba, M. The Effects of Altitude Training on Erythropoietic Response and Hematological Variables in Adult Athletes: A Narrative Review. Frontiers in physiology, 9, 375, 2018

[4] High-Intensity Functional Training Related to Changes in Associated Physiologic Measures? Sports, 6, 26, 2018

[5] Linthorne, N.P. Improvement in 100-m Sprint Performance at an Altitude of $2250 \mathrm{~m}$. Sports, 4, 29, 2016

[6] Hamlin, M.J.; Lizamore, C.A.; Hopkins, W.G. Correction to: The Effect of Natural or Simulated Altitude Training on High-Intensity Intermittent Running Performance in Team-Sport Athletes: A Meta-Analysis. Sports Medicine, 48(5), 1289-1291, 2018

[7] Lobigs, L.M.; Sharpe, K.; Garvican- Lewis, L.A.; Gore, C.J.; Peeling, P.; Dawson, B.; Schumacher, Y.O. The athlete's hematological response to hypoxia: A metaanalysis on the influence of altitude exposure on key biomarkers of erythropoiesis. American journal of hematology,93(1), 74-83,2018

[8] Garvican-Lewis, L.A.; Halliday, I.; Abbiss, C.R.; Saunders, P.U.; Gore, C.J. Altitude exposure at $1800 \mathrm{~m}$ increases haemoglobin mass in distance runners. Journal of sports science \& medicine, 14(2), 413, 2015

[9] Ferran, A.; RodrõÂguez, J.L.; Ventura, M.C. Erythropoietin acute reaction and haematological adaptations to short, intermittent hypobaric hypoxia. Eur J ApplPhysiol, 82, 170-177, 2000

[10] Flaherty, G.; O'Connor, R.; Johnston, N. Altitude training for elite endurance athletes: A review for the travel medicine practitioner. Travel medicine and infectious disease, , 14(3), 200-211, 2016

[11] Gledhill, N.; Warburton, D.; Jamnik, V. Haemoglobin, blood volume, cardiac function, and aerobic power. Canadian journal of applied physiology, 24(1), 54-65, 1999

[12] Gore, C.J.; Sharpe, K.; Garvican-Lewis, L.A.; Saunders, P.U.; Humberstone, C.E.; Robertson, E.Y.; Neya, M. Altitude training and haemoglobin mass from the optimised carbon monoxide rebreathing method determined by a meta-analysis. Br J Sports Med, 47(Suppl 1), 31-39, 2013

[13] Sinex, J.A.; Chapman, R.F. Hypoxic training methods for improving endurance exercise performance. Journal of Sport and Health Science, 4(4), 325-332, 2015

[14] Wilber, R.L. Application of altitude/hypoxic training by elite athletes. Medicine \& Science in Sports \& Exercise, 39(9), 1610-1624, 2007

[15] Garvican, L.; Martin, D.; Quod, M.; Stephens, B.; Sassi, A.; Gore, C. Time course of the hemoglobin mass response to natural altitude training in elite endurance cyclists. Scandinavian journal of medicine \& science in sports, 22(1), 95-103, 2012

[16] Neya, M.; Enoki, T.; Ohiwa, N.; Kawahara, T.; Gore, C.J. Increased hemoglobin mass and $\mathrm{VO} 2$ max with $10 \mathrm{~h}$ nightly simulated altitude at $3000 \mathrm{~m}$. International journal of sports physiology and performance, 8(4), 366-372, 2013

[17] Saunders, P.U.; Pyne, D.B.; Gore, C.J. Endurance training at altitude. High altitude medicine \& biology, 10(2), 135-148, 2009

[18] Asano, M.; Kaneoka, K.; Nomura, T.; Asano, K.; Sone, H.; Tsurumaru, K.; Okuda, Y. Increase in serum vascular endothelial growth factor levels during altitude training. Acta physiologica scandinavica, 162(4), 455-459,1998

[19] Friedmann, B.; Jost, J.; Weller, E.; Werle, E.; Eckardt, K.U.; Bartsch, P.; Mairbaurl, H. Effects of iron supplementation on total body hemoglobin during endurance training at moderate altitude. International journal of sports medicine, 20(02), 78-85, 1999

[20] Nadarajan, V.S.; Ooi, C.H., Sthaneshwar, P.; Thompson, M. W. The utility of immature reticulocyte fraction as an indicator of erythropoietic response to altitude training in elite cyclists. International journal of laboratory hematology, 32(12), 82-87, 2010

[21] Brosnan, M.J.; Martin, D.T.; Hahn, A.G. Impairedintervalexerciseresponsesin elite femalecyclists at moderate simulated altitude. J Appl Physiol, 89, 1819-1824, 2000

[22] Weil, J.V.; Jamieson, G.; Brown, D.W.; Grover, R. F. The red cell mass-arterial oxygen relationship in normal man: application to patients with chronic obstructive airway disease. The Journal of clinical investigation, 47(7), $1627-1639,1968$

[23] Frese, F.; Friedmann-Bette, B. Effects of repetitive training at low altitude on erythropoiesis in 400 and 800 m runners. International Journal of Sports Medicine, 31(06), 382-388, 2010

[24] Pottgiesser, T.; Ahlgrim, C.; Ruthardt, S.; Dickhuth, H.H.; Schumacher, Y.O. Hemoglobin mass after 21 days of conventional altitude training at $1816 \mathrm{~m}$. Journal of science and medicine in sport, 12(6), 673-675, 2009

[25] Rusko, H.K.; Tikkanen, H.O.; Peltonen, J. E. Oxygen manipulation as an ergogenic aid. Curr Sports Med Rep, 2(4), 233-8, 2003

[26] Gore, C.J.; Hahn, A.G.; Burge, C.M.; Telford, R.D. VO2max and haemoglobin mass of trained athletes during high intensity training. International journal of sports medicine, 28(06), 477-482, 1997 
[27] Badau, D.; Bacarea, A.; Ungur, R.N.; Badau, A.; Martoma, A.M. Biochemical and functional modifications in biathlon athletes at medium altitude training. Revista Romana de Medicina de Laborator, 24(3), 327-335, 2016

[28] Gore, C.J.; Clark, S.A.; Saunders, P.U. Nonhematological mechanisms of improved sea-level performance after hypoxic exposure. Medicine \& Science in Sports \& Exercise39(9), 1600-1609, 2007

[29] Saunders, P.U.; Garvican-Lewis, L.A.; Schmidt, W.F.; Gore, C.J. Relationship between changes in haemoglobin mass and maximal oxygen uptake after hypoxic exposure. British Journal of Sports Medicine, 47(Suppl 1), 26-30, 2013
[30] Heinicke, K.; Heinicke, I.; Schmidt, W.; Wolfarth, B. Three-week traditional altitude training increases hemoglobin mass and red cell volume in elite biathlon athletes. International journal of sports medicine, 26(05), $350-355,2005$

[31] Clark, S.A.; Quod, M.J.; Clark, M.A.; Martin, D.T.; Saunders, P.U.; Gore, C.J. Time course of haemoglobin mass during 21 days live high: train low simulated altitude. European journal of applied physiology,106(3), 399-406, 2009 